\title{
Design and Simulation of Coordinated Speed Controller for Multiple Electrically Excited Synchronous Motors
}

\author{
J. Tsado' , A. U. Usman², J. S. Adeshina ${ }^{3 *}$ \\ 1,2,3 Department of Electrical/Electronic Engineering, Federal University of Technology Minna, Niger State, \\ Nigeria \\ *Corresponding Author: Jimoh Saheed Adeshina, Department of Electrical/Electronic Engineering, \\ Federal University of Technology Minna, Niger State, Nigeria
}

\begin{abstract}
This study is focused on the design and simulation of coordinated speed controllers for multiple electrically excited synchronous motors (EESMs). The mathematical modeling representing the multiple electrically excited synchronous motors was developed using physical modeling in which the dynamic nature and the non-linear effect between electrically excited synchronous motors was considered. The model was then used to design a controller in order to coordinate the speed of the electrically excited synchronous motors through cross coupling techniques in which speed and current signals of the motors were all taken as cross-feedback signal and the interval matrix was used to set parameters boundary. The controller designed and the traditional proportional integral (PI) controller were compared by simulation using MATLAB Simulink program and the results shows that the designed controller has a better control performance with smaller overshoot of $0.34 \%$ and smaller synchronization error of 0.11 rpm as compared to PI controller which have overshoot of $0.88 \%$ and synchronization error of $0.36 \mathrm{rpm}$.
\end{abstract}

Keywords: Electrically Excited Synchronous Motors (EESM), cross coupling, coordinated speed controller, synchronization.

\section{INTRODUCTION}

Direct current electric machine systems had been adopted in a variety of industrial applications for more 100 years for convenience of torque and speed control. During the past 30 years, with the development of power electronics, digital signal processors (DSPs), and computer-aided design technologies, AC motors have replaced DC motors and have become dominant in variable frequency motor applications. Currently, various types of AC motors like induction motor (IM), electrically excited synchronous motor (EESM) or permanent magnet synchronous motor (PMSM) and switched reluctance machines (SRM) are widely used in mine-hoisting, metallurgy, metal-rolling, bottling system and marine propulsion, particularly in the field of high-power industrial drives [1].

Among the AC motors, EESM systems have been used more and more for coupling multi-motor systems in industry, agriculture and transportation especially in bottling company due to their distinctive advantages of high efficiency, high power density, high overload capacity and good performance in the field weakening area than asynchronous induction motors. However, coupling multi-motor systems require good coordination to achieve good production quality, reduce contouring errors, and improve the operation security of systems [2].

Speed controls are an essential part of modern machinery. A challenging problem is that the speed of multiple motors needs to be controlled in synchronous manner and the couplings among motors need to be coordinated because of the influences among the coupling motors when their rotor angular positions are different. Therefore, the coupling between motors should be considered when a model of electrically excited synchronous motors is to be established.

Also, the cost of the additional sensors and timing hardware to produce sensor-based controller for EESMs is minimal compared to the tremendous benefits they provide for the performance and efficiency of the system. Conventional controller however has some disadvantages including chattering phenomenon, and inaccurate rotor position information which will not only degrade the control performance but also cause instability in the control system. Robustness properties against 
various kinds of uncertainties such as parameter perturbations and load torque disturbances can also not be guaranteed in conventional controllers. Therefore, to solve these problems, this paper presents a comprehensive study of the higher order cross couple methods of speed control for EESM, which ensure robustness against a load torque disturbance and parameter variation with chattering reduction.

In recent decades, many coordination controls have been designed for multiple motor systems : Koren and Lo [3]; Srinivasan and Kulkami [4], implemented fixed cross coupled controllers to reduce the contour error of two motion axes in machine tool control. Likewise, a cross-coupling generalized predictive control with reference models was also presented by Zhu and Chen [5], which can effectively handle various processes of multiple motion axes by compensating the tracking error. Similarly, Sun [6] designed a Position synchronization controller for multiple motion axes with adaptive coupling control. He developed a control approach to position synchronization of multiple motion axes by incorporating cross-coupling technology into adaptive control design. To track different desired trajectories, the work by Xiao, Zhu and Liaw [7], exploited a generalized synchronization controller for multi-axis motion systems by integrating cross-coupling technology into optimal control architecture. Barton and Alleyne [8] also achieved precision motion control by combining individual axis iterative learning control (ILC) and cross-coupled ILC into a single control input. In a related development, Zhang et al [9] developed a chaotic speed synchronization controller for multiple induction motors using stator flux regulation (SFR) by using direct torque control (DTC) through the stator flux regulation with a non-linear control approach.

However, the principal shortcoming of existing control techniques lie on their inability to incorporate plant model uncertainty so as to provide better synchronization performance as well as the numerous advantages EESMs have over induction motors as utilized in this work for multiple EESMs speed control to achieve better performance.

This paper contains five sections. The first section generally presents the introduction of the speed control of EESM using cross coupling method with interval matrix for the design of coordinated speed controller which serve as the background of the EESM speed control, problem statement and outline of the paper. Section two presents research methodology. Simulation results are presented and discussed in section three. Finally, section four presents conclusion.

\section{ReSEARCH Methodology}

This section describes the mathematical model of the EESM, Rectifier and PWM Inverter, Flux observer, cross couple control, Speed tracking controller and Speed Synchronization Controller.

\subsection{Mathematically Model of the Eesm}

According to Chen et al (2003), taking into consideration the model error and disturbance the dynamic, he mathematical model of EESMs can be described as follows:

$$
\begin{aligned}
& \left\{\frac{d i_{s q}}{d t}=-\frac{R_{s i}}{\sigma_{i} L_{s d i}} i_{s d i}+\frac{L_{s q i} R_{f}}{\sigma_{i} L_{s d i}} \omega_{i} i_{s q i}+\frac{L_{m d i} R_{f t}}{\sigma_{i} L_{s d i} L_{f t}} i_{f t}+\frac{1}{\sigma_{i} L_{s d i}} u_{s d i}-\frac{L_{m d i}}{\sigma_{i} L_{s d i} L_{f i}} u_{f}+d_{d i}\right. \\
& \left\{\frac{d i_{s q i}}{d t}=-\frac{L_{s d i}}{L_{s q i}} \omega_{i} i_{s d i}-\frac{R_{s t}}{L_{s q i}} i_{s q i}-\frac{L_{m d i}}{L_{s q i}} \omega_{i} i_{f t}+\frac{1}{L_{s q i}} u_{s q i}+d_{q i}\right. \\
& \frac{d \omega_{1}}{d t}=\frac{n_{p i}^{2}}{J_{1}}\left(L_{m d i} I_{f t} i_{s q i}-\left(L_{m d i}-L_{m q i}\right) i_{s d i} i_{s q i}\right)-\frac{n_{p i}}{J_{i}} T_{i t}-\frac{n_{p i} B_{i}}{J_{i}} \omega_{i}+d_{\omega i},
\end{aligned}
$$

where $\mathrm{L}_{\mathrm{sdi}}$ and $\mathrm{L}_{\mathrm{sqi}}$ are the $\mathrm{d}$ - and q-axis self-inductions of motor $\mathrm{i}$, respectively; $\mathrm{L}_{\mathrm{mdi}}$ and $\mathrm{L}_{\mathrm{mqi}}$ are the $\mathrm{d}$ - and $\mathrm{q}$-axis mutual inductances of motor $\mathrm{i}$, respectively; $\mathrm{L}_{\mathrm{fi}}$ is the excitation winding self induction of motor $i ; \sigma=1-\left(L_{m d i \wedge}\right) /\left(L_{s d i} L f i\right)$ is the leakage coefficient of motor $i ; R_{f i}$ is the excitation winding resistance of motor $i ; R_{s i}$ is the stator resistance of motor $i ; n_{p i}$ is the number of pole pairs of motor $i$; $B_{i}$ is the frictional coefficient; $J_{i}$ is the moment inertia of motor $i ; i_{i}$ is the excitation current of motor $\mathrm{i}$; $\mathrm{i}_{\mathrm{sdi}}$ and $\mathrm{i}_{\mathrm{sqi}}$ are the $\mathrm{d}$ and $\mathrm{q}$-axis currents of motor $\mathrm{i}$ respectively; $\omega \mathrm{i}$ is the rotor angular speed of motor $\mathrm{i}$; ufi is the excitation voltage of motor $\mathrm{i}$; $\mathrm{u}_{\mathrm{sdi}}$ and $\mathrm{u}_{\mathrm{sqi}}$ are the $\mathrm{d}$ and $\mathrm{q}$-axis input voltages of motor $i$ respectively; $T_{i}$ is the load torque; $d f i, d_{d i}, d_{q i}$ and $d\left(\omega_{i}\right)$ present the model error and disturbance; and subscript $\mathrm{I}=1, \cdots, \mathrm{n}$.

\subsection{Rectifier and PWM Inverter}

The first system that was modelled in this work was the power supply to the motor as shown in Figure 2.1

International Journal of Research Studies in Electrical and Electronics Engineering (IJRSEEE) Page | 43 


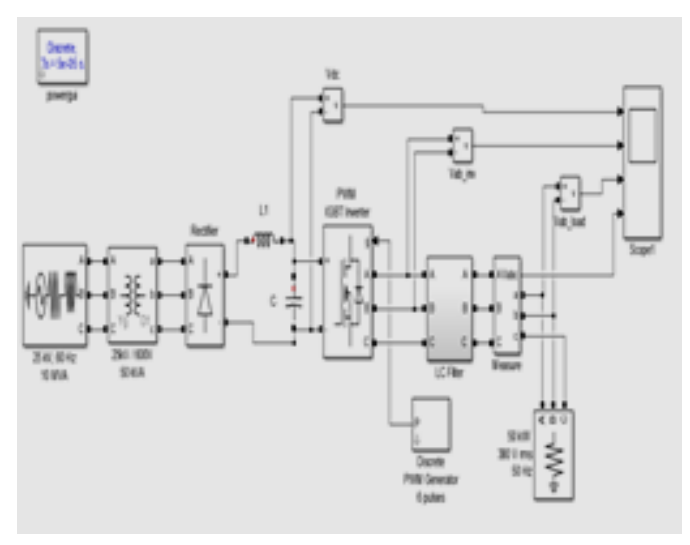

Figure2.1. $A C-D C-A C$ Conversion

The model converts the AC signal from the source to a DC signal using a diode rectifier. To be able to control or regulate the speed of the motor the system which has to be converted back to AC but this time the AC voltage is controlled by the duty cycle generated to switch ON and OFF the power IGBT. By switching, the AC signal is regulated.

\subsection{Flux Observer}

Flux observer is employed to estimate the rotor flux and the rotor flux angle in order to implement rotor field orientation

$$
\begin{aligned}
& \psi_{d r}=-\alpha \dot{\psi}_{d r}+\alpha M l_{d s} \\
& \theta_{e}=n_{p} \omega+\frac{\alpha M i_{d s}}{\psi_{d r}}
\end{aligned}
$$

where $\theta_{\mathrm{e}}$ is the rotor flux angle, $\omega$ is the rotor angular speed of motor, and $\psi_{\mathrm{dr}}$ is the d-axis rotor flux with the use of this observer, numerical differentiation is avoided which normally result to noise and subsequent degradation of the closed-loop system performance, the flux observer is almost mandatory by many control schemes popular today due to the fact that closed loop system performance is robust with respect to parameters deviation and uncertainties. The flux observer was modelled based on the equations provided above and it is shown in Figure 2.2

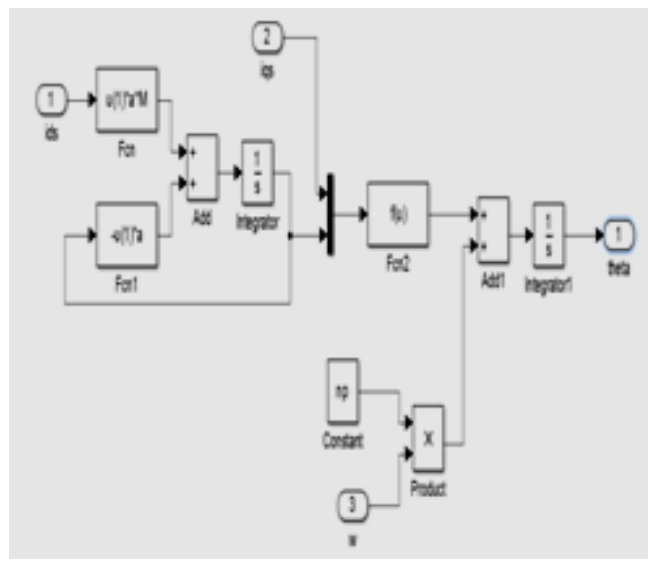

Figure2.2. Flux Observer

\subsection{Cross-Coupling Control}

Considering n-motor system, the dynamic model of every motor is given by equation 2.3 different parameters. The speed tracking error of motor " $i$ " is defined as:

$e_{i, i}(t)=\omega_{i}(t)-\omega^{*}(t)$

where, the reference speed $\omega^{*}$ is the same for all motors. In the synchronisation motion, besides, it is also aimed to regulate the output speed of the motors to satisfy

International Journal of Research Studies in Electrical and Eectronics Engineering (IJRSEEE) Page | 44 
$\omega_{1}(t)=\cdots \omega_{i}(t)=\cdots \omega_{n}(t)$

The speed synchronisation errors of motor $i$ with its two adjacent motors from the total of $n$ motors is then described by equation 2.4

$e_{i, i+j}(t)=\omega_{i}(t)-\omega_{i+j}(t)$

Where, $j=-1$ is for the previous motor $(i-1)$ and $j=1$ is for the next motor $(i+1)$.

If $e_{i, i+j}(t)=0$ for $\mathrm{i}=1 \ldots \mathrm{n}$, then equation representing speed synchronization error is held. The relevant speed synchronisation errors of motor $i$ are $e_{i, i+1}(t)$ and $e_{i, i-1}(t)$ which converge to zero fast. Thus, there is need to synchronise motions of motor $i$ with motor $(i-1)$ and motor $(i+1)$. The speed controller of motor i includes three sub controllers: one speed tracking controller $C_{i, i}$ which is used to track the reference speed signal accurately and two speed synchronisation controllers $C_{i, i+1}$ and $C_{i, i-1}$, which are used to synchronise the output speed of the controlled motor i with its adjacent motor (i - 1 ) and motor $(i+1)$, respectively. The proposed control strategy on motor i consider motion responses of its two adjacent motors, but not all other motors, for synchronisation. This significantly simplifies the implementation especially when the number of motors is large.

The structure of the speed controller of motor $\mathrm{i}$ is shown in Figure 2.3, where $i_{q s(i, i)}^{*}(t)$ is the command current for speed tracking, $i_{q s(i, i-1)}^{*}(t)$ and $i_{q s(i, i+1)}^{*}(t)$ are the command currents for speed synchronisation and $i_{q s(i)}(t)$ is the complete stator current command of motor $\mathrm{i}$.

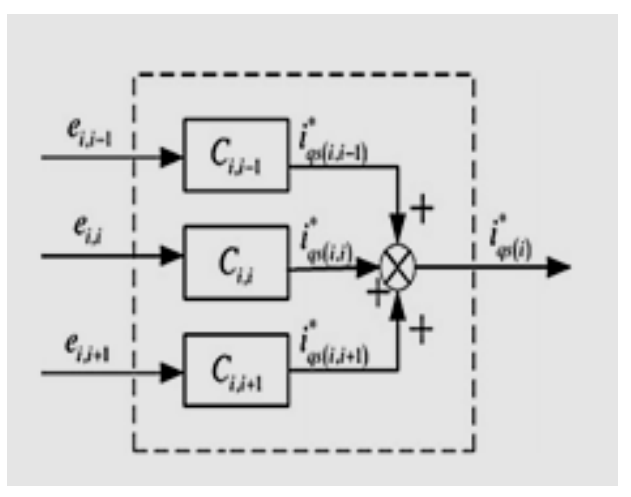

Figure2.3. Structure of speed controller of motor $i$

While Figure 2.4 illustrates the general system block diagram using cross couple controls method. The system basically includes flux observer and three other major sub systems (i.e. individual controller for each axis which includes the speed controller, synchronization and tracking speed error sub- system). The system also includes different co-ordinate transformation, such as Clarke, Park and IPark for the purpose of vector control. Pulse width modulation (PWM) is also part of the system which calculates the operation time of the inverter gates from the controlled d-q space vector voltage value for proper application voltages on the stator windings. The controller attains the required value of set point by using measured stator currents and speed as feedback value.

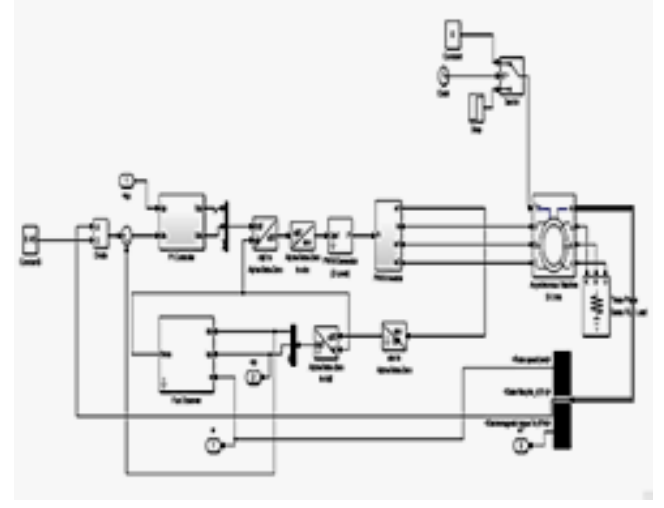

Figure2.4. Structure model of motor $i$

International Journal of Research Studies in Electrical and Electronics Engineering (IJRSEEE) Page | 45 
The overall MATLAB SIMULINK model of the EESMs allows simulating the behaviour of the machine using unity feedback and cross couple controller designed follow with PI controller for different operating modes. The results were obtained by simulation of the designed model in MATLAB by varying the loads $\left(\mathrm{T}_{\mathrm{L}}\right)$. The desired speed of the motors were set at $27 \mathrm{r} / \mathrm{m}$ while load was added to the system at $0.3 \mathrm{~s}$ and removed at $1 \mathrm{~s}$. The simulation is based on discrete system with sampling period of $10 \mu \mathrm{s}$. The PWM frequency is set as $10 \mathrm{kHz}$ and the DC-link voltage is $400 \mathrm{~V}$.

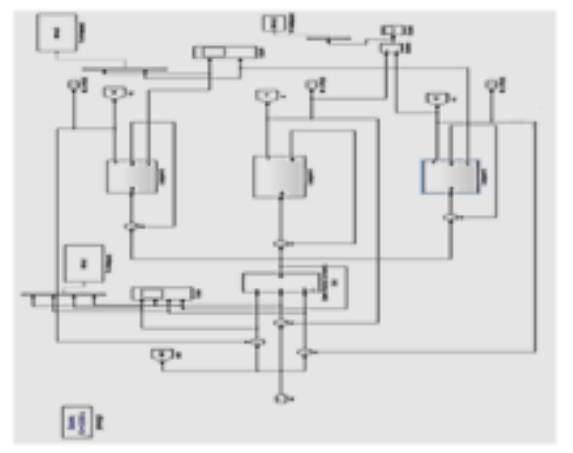

Figure2.5. Model configuration of multiple EESMs

\section{Results AND Dis CUSSiON}

\subsection{Result}

Figures 3.1 and 3.2 Shows the performance of the designed controller compared with PI controller in terms of speed, maximum synchronization error (MSE) and overshoot. While Figure 3.3 and 3.4 shows the speed, the torque and the stator current with respect to time for designed controller without load and load condition The control performance of a traditional PI controller was depicted in Figure 3.2 , which shows the speed error at maximal $(0.36 \mathrm{r} / \mathrm{m})$ when the load is changed. Figure 3.1 shows the results indicating maximum speed error of $0.11 \mathrm{r} / \mathrm{m}$.

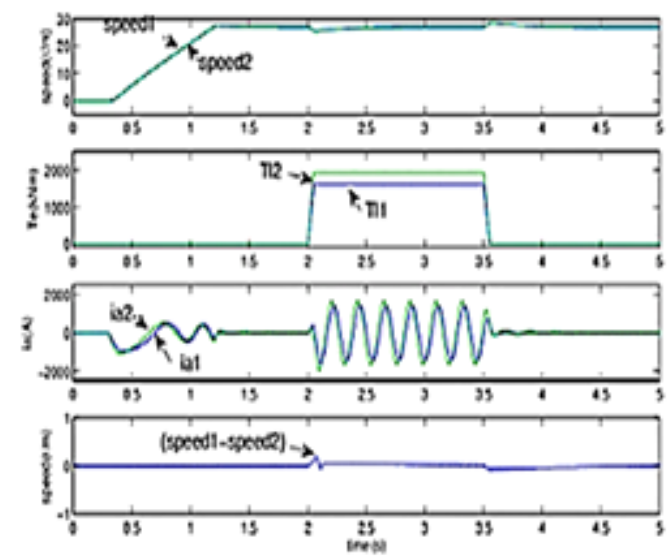

Figure3.1. Performance of designed controller with load.

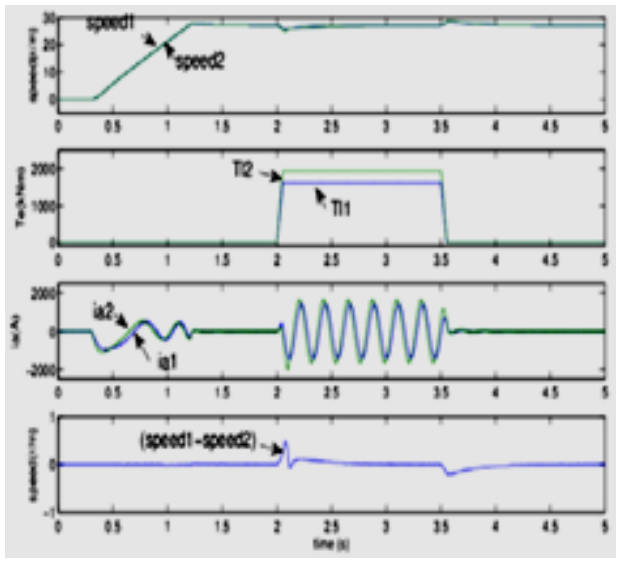

Figure3.2. Performance of PI controller with load. 

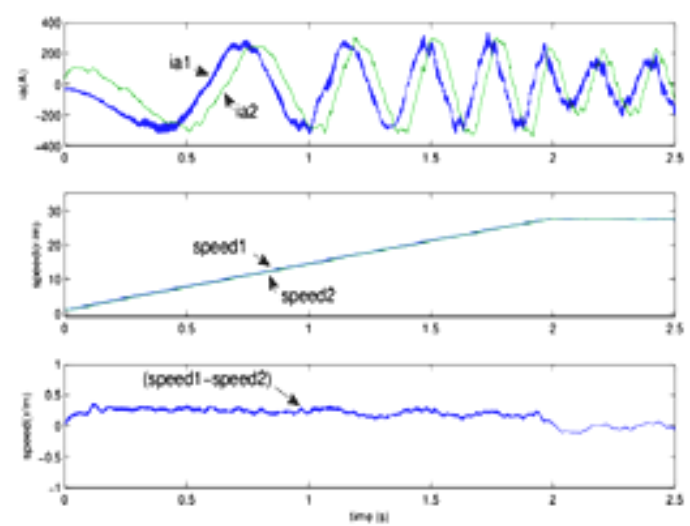

Figure3.3. Designed controller without load.

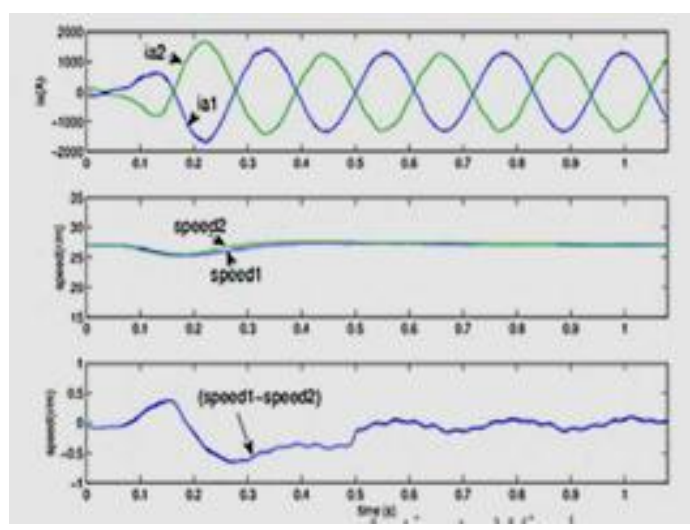

Figure3.4. Designed controller with load.

\subsection{Discussion of Result}

The observed maximal speed error was $0.11 \mathrm{r} / \mathrm{m}$ for designed controller while $0.36 \mathrm{r} / \mathrm{m}$ was observed for PI controller, which proves the effectiveness of the control method when the parameters and loads of the motors are different. This result indicates that the designed controller exhibits a superior performance relative to the traditional PI controller.

The results indicated that regardless of whether the system is in steady state or dynamic state, the speed error between the motors is nearly zero. When the motor touches the load, the maximum speed error between the motors is less than $0.7 \mathrm{rpm}$, and the error converges to nearly zero in a short time. Hence, the speed error and the synchronization error tend to zero quickly in the case of designed controller when the desired speed is varied between 0.3 and 1s and at the same time, the overshoot and the maximum synchronization error (MSE) are very small as summarised in table 1 which shows that the setting time of the designed controller method using cross couple method is shorter than that of the conventional PI control method; the overshoot and the maximum synchronization error of the designed controller are smaller than that of the conventional PI control method. In general, the performance indexes of the proposed control method are better than that of the conventional PI control method under the two conditions; especially the maximum synchronization error of the proposed method is clearly smaller than the conventional PI control method. These reflects the correct and effectiveness of the cross couple control method.

Table1. Comparison of control methods

\begin{tabular}{|c|c|c|c|c|}
\hline Condition & & & Controller & \\
\hline & & Designed & & PI \\
\hline & Settling time & $0.0163 \mathrm{~s}$ & & $0.0173 \mathrm{~s}$ \\
\hline & Overshoot & $0.34 \%$ & & $0.88 \%$ \\
\hline & MSE & $0.11 \mathrm{r} / \mathrm{m}$ & & $0.36 \mathrm{r} / \mathrm{m}$ \\
\hline Case 2 & Settling time & 0 & & 0 \\
\hline & Overshoot & $0.76 \%$ & & $1.89 \%$ \\
\hline & MSE & $<0.7 \mathrm{r} / \mathrm{m}$ & & $>2.5 \mathrm{r} / \mathrm{m}$ \\
\hline
\end{tabular}

International Journal of Research Studies in Electrical and Electronics Engineering (IJRSEEE) Page | 47 
Therefore, this result indicates that the designed controller exhibits a superior performance compared to the traditional PI controller. Other advantages are that the load information of two motors is not required in the designed controller and that the designed controller can deal with load uncertainty.

\section{CONCLUSiON}

This research work is based on coordination control strategy for multiple EESM systems via cross coupling techniques and an interval matrix. Mathematical model of the system was established, and then, utilized to design and model a coordination controller using cross coupling control techniques in which the dynamic model of EESMs and the nonlinear coupling effect between multiple synchronous motors were considered in modelling the system. The current signals of EESMs, together with the speed error signals and the position signals, were also taken as the cross-feedback signals in the system model. Because of these, the designed controller system demonstrated better dynamic performance and synchronization performance as compared to the traditional PI controller using simulation result obtained (i.e. designed controller have smaller overshoot of $0.34 \%$ and smaller synchronization error of $0.11 \mathrm{rpm}$ as compared to PI controller with overshoot of $0.88 \%$ and synchronization error of $0.36 \mathrm{rpm})$. Hence, the designed system can work with different load torque and different environment condition at the same time reduce chattering effect of multiple EESMs, future work should be focused on improving the robustness of designed controller, decreasing the influence of drastic change of load on control performance, and designing optimal controller for this system. Besides, generalized coordinating controller should be designed for multiple EESMs, which implies the desired speed of two motors may be different.

\section{REFERENCES}

[1] Leonhard W. (2001), Control of Electrical Drives, pp. 1523-1528, 3rd Edition, Springer, Berlin

[2] Yue .Z. (2014), Position/speed sensor-less control for permanent-magnet synchronous machines, Electrical Engineering Theses and Dissertations University of Nebraska-Lincoln

[3] Koren, Y., \& Lo, C.-C., (1991), "Variable-Gain Cross-Coupling Controller for Contouring," CIRP Ann., pp.371-374

[4] Srinivasan K.\&Kulkarni P., (1990) "Cross-coupled compensators for contouring control of multi-axial machine tools," in Proc. 13th North American Manufacturer Res. Conf., pp. 558-566

[5] Zhu, K. Y. \& Chen, B. P. (2001), Cross-coupling design of generalized predictive control with reference models. Proceedings of the Institution of Mechanical Engineers Part I, pp. 375-384.

[6] Sun, D. (2002), "Position synchronization of multiple motion axes with adaptive coupling control," Automatica, Vol. 39, No.6, pp. 997-1005

[7] Xiao Y. Zhu K. Y. \& Liaw, H. C., (2005), "Generalized Synchronization Control of Multi-Axis motion systems," Control Eng. Pract., 13(7), pp. 809-819.

[8] Barton K. L. \& Alleyne A. G. (2008), “A cross-coupled iterative learning control design for precision motion control," IEEE Trans. Control Syst. Technol., Vol. 16, No. 6, pp.1218-1231

[9] Zhang, Z., Chau, K. T., \& Wang, Z. (2012). Chaotic Speed Synchronization Control Of Multiple Induction Motors Using Stator Flux Regulation. IEEE Transactions on Magnetics, 48(11), 4487-4490. https://doi.org/10.1109/TMAG.2016.2197376

\section{AUTHORS' B IOGRAPHY}

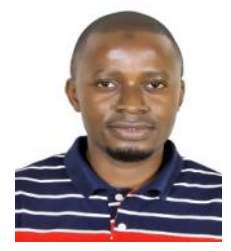

Jimoh Saheed Adeshina, B. Eng degree in Electrical and Computer Engineering and a M. Eng. degree in Electrical Engineering (Electrical Power System and Machine emphasis) along with the teaching experience in a reputable college for some years now.

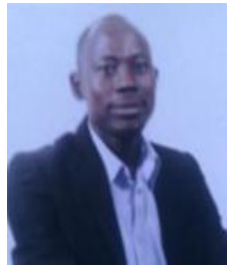

A. U. Usman, is a Senior Lecturer with the Department of Electrical and Electronics Engineering, Federal University of Technology, Minna, Nigeria. He obtained his B.Eng. degree in Electrical \& Computer Engineering from the same University in 1998. He acquired M.Sc. in Electrical Engineering from University of Lagos, Nigeria and $\mathrm{PhD}$ in Communication Engineering from Abubakar Tafawa Balewa University, Bauchi Nigeria in 2002 and 2014 respectively. 
He is currently the Departmental Post graduate coordinator and the Deputy Dean, School of Electrical Engineering and Technology. He has teaching experience in the area of mobile radio propagation modeling, wireless communication system, wireless network resource utilization, numerical methods, and digital electronics. His research interest includes radio propagation modelling, indoor and outdoor wireless communication and application of Artificial Intelligent techniques in Electrical Engineering. He has published several papers in national/international journal and conferences.

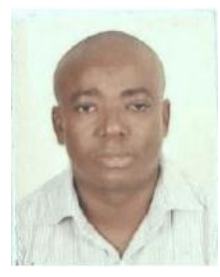

J. Tsado, obtained his Bachelor of Engineering Degree (B. Eng.) in Electrical \& Computer Engineering from Federal University of Technology Minna, Nigeria in 1998. He also obtained M. Eng and Ph.D in Electrical Power System \& Machine from University of Benin, Benin city,Nigeria in 2001 and 2007 respectively.

$\mathrm{He}$ is an Associate Professor and the current Head of Department for Electrical and Electronics Engineering, Federal University of Technology Minna, Nigeria, since December 2016. He was the Industrial liaising officer of Federal University of Technology, Minna between 2009 to 2011 and was the Head of Department Computer Engineering at Federal University of Technology, Minna between 2011 and 2012. He has authored and co-authored quite number of published journal papers and conference proceeding. His research area is power system and energy studies with special interest in Protection Schemes. Engr. Dr. Tsado was a member of IEEE, Nigerian Society of Engineers (NSE) and a Council for the Regulation of Engineering in Nigeria (COREN) registered engineer. $\mathrm{He}$ is also an editorial member of the Engineering Journal of the Federal University of Technology, Minna. He recently received an award for excellence from Nigerian Society of Engineers (NSE) Minna Branch, in her quarterly public lecture held at Shiroro Hydro Generation Station, Niger State.

Citation: J. Tsado et.al, "Design and Simulation of Coordinated Speed Controller for Multiple Electrically Excited Synchronous Motors", International Journal of Research Studies in Electrical and Electronics Engineering, 4(1), pp 42-49. DOI: http://dx.doi. org/10.20431/2454-9436.0401005

Copyright: (C) 2018 J. Tsado. This is an open-access article distributed under the terms of the Creative Commons Attribution License, which permits unrestricted use, distribution, and reproduction in any medium, provided the original author and source are credited. 